\title{
Assessment of healthcare professionals' perceptions and attitudes towards the COVID-19 pandemic in Turkey
}

\author{
Halil Türktemiz ${ }^{\mathrm{a}, 1}$, Özgün Ünal ${ }^{\mathrm{b}, 2, *}$ and Dilek Bingöl Aydın ${ }^{\mathrm{c}, 3}$ \\ ${ }^{a}$ Medical Imaging Techniques, Vocational School of Health Services, KTO Karatay University, Konya, Turkey \\ ${ }^{\mathrm{b}}$ Department of Healthcare Management, Faculty of Business, Sakarya University, Sakarya, Turkey \\ ${ }^{\mathrm{c}}$ Training and Research Hospital, Department of Pediatrics, Sakarya University, Sakarya, Turkey
}

Received 8 December 2020

Accepted 15 June 2021

\begin{abstract}
.
BACKGROUND: Determining the healthcare professionals' perceptions and attitudes towards the COVID-19 pandemic will contribute to managing and struggling their efforts against COVID-19.

OBJECTIVE: This study aimed to determine the perceptions and attitudes of healthcare professionals who are at the forefront in the fight against this pandemic.

METHODS: In the study, the survey technique used as the data collection method and 216 participants agreed to participate. The questionnaire consisted of three sections. Reliability analysis and descriptive statistical methods used to analyze the data obtained using the SPSS package program.

RESULTS: According to the study results, $80.4 \%$ of the participants perceive the probability of being infected with the COVID-19 to be very high, and $64 \%$ of them consider that the conditions are very favorable for them to be infected. More than half of them are afraid of being infected and believe that if they contract COVID-19, adverse effects may continue for a long time. Furthermore, almost all participants (96.20\%) consider personal protective equipment beneficial and will protect them from the COVID-19 as a wise preventive measure. However, $82.30 \%$ of the participants stated that using personal protective equipment is uncomfortable, and $76.60 \%$ said it is challenging to take care of patients while using personal protective equipment.

CONCLUSIONS: The current study results show that healthcare professionals are aware of how serious COVID-19 is, understand the importance of protective equipment in protection from COVID-19, and are seriously afraid of COVID19. Given that the fears of healthcare professionals may have adverse effects on them, it is recommended that healthcare administrators take measures to comfort healthcare workers and ensure that they maintain their positive attitude towards COVID-19.
\end{abstract}

Keywords: COVID-19 pandemic, healthcare professionals' challenges, fear of COVID-19, personal protective equipment, stigma and avoidance

\footnotetext{
${ }^{1}$ E-mail: halilturktemiz@gmail.com, ORCID: orcid.org/00000001-8920-8120

${ }^{2}$ E-mail: ozgununal@ sakarya.edu.tr, ORCID: orcid.org/00000002-1245-2456

${ }^{3}$ E-mail: dilekbingol@ hotmail.com, ORCID: orcid.org/00000001-6064-9205

*Address for correspondence: Özgün Ünal, Faculty of Business, Sakarya University, 54187 Esentepe Campus, Serdivan,
}

\section{Introduction}

COVID-19 has affected the whole world since the day it emerged. Due to its rapid transmission rate, the World Health Organization declared it a pandemic

Sakarya, Turkey. Tel.: +90 55364496 90; E-mail: ozgununal@ sakarya.edu.tr. 
on 11 March 2020 [1]. The COVID-19 pandemic has increased the need for healthcare professionals and healthcare services. Accordingly, the responsibilities of healthcare professionals have increased significantly. Healthcare professionals of all levels and groups are involved in the care of COVID-19 patients [2]. Physicians, nurses, and other healthcare professionals, who play an essential role in preventing the spread of the COVID-19 pandemic, are at risk of contracting the disease because they serve infected patients even if they have adequate protective equipment [3-5]. The problems faced by healthcare workers increase with the quarantine of infected healthcare workers and their inability to perform their profession for a few weeks [6]. The extraordinary density in hospitals due to COVID-19 also increases the workload of healthcare workers [7]. These situations show that healthcare workers face many difficulties in combating the pandemic.

Healthcare professionals who are heavily serving COVID-19 patients must have sufficient knowledge about COVID-19 [8]. However, the insufficient level of knowledge of healthcare professionals about COVID-19 can lead to the formation of false perceptions and attitudes against COVID-19, delay in diagnoses, ineffective control of infection, and the spread of the disease [9-11]. For this reason, it is essential to determine the COVID-19 perceptions and attitudes of healthcare professionals who reveal their lives while performing their duties. In addition, understanding healthcare professionals' knowledge and attitudes towards COVID-19 also help predict COVID-19 consequences $[12,13]$. Therefore, determining the perceptions and attitudes of healthcare professionals about COVID-19 will contribute to managing the COVID-19 pandemic. From this idea, this study aimed to determine the perceptions and attitudes of healthcare professionals who are at the forefront of the fight against the COVID-19 pandemic. The research question developed in line with the aim of the study is as follows:

How are healthcare professionals' perceptions and attitudes towards the COVID-19 pandemic shaped?

\section{Methods}

The study sample included 815 physicians, 990 nurses, and 600 other healthcare professionals affiliated with Sakarya Provincial Health Directorate and work in Sakarya Training and Research Hospital, one of the two pandemic hospitals in Sakarya. As only one campus of the hospital designated as a pandemic hospital, the study conducted on only this campus. This campus has 523 employees ( 153 physicians, 220 nurses, 150 other healthcare professionals). Therefore, we aimed to reach the whole sampling, and 216 (32 physicians, 61 nurses, 123 other healthcare professionals) participants filled out the questionnaire statements. In this study, a survey technique used as the data collection method. The questionnaire consisted of three sections:

1. In this part, there were eight questions to determine the employees' demographic information and opinions, including age, gender, educational status, number of children, type of profession, professional experience, number of COVID-19-positive healthcare professionals in their units, and whether the measures taken against the COVID-19 are sufficient.

2. Health Belief Model Scale. Champion [14] developed this scale, which was initially composed of 5 dimensions and 39 expressions and measured individuals' health beliefs related to lung cancer. Then, it was used by Bova [15] to measure health beliefs related to tuberculosis. In this study, the scale adapted from that used by Bova [15]. However, the motivation dimension, which is the last dimension of the scale, was not utilized because it measures longterm attitudes. In this study, the susceptibility (6 expressions), seriousness (12 expressions), benefit (5 expressions), and barriers (8 expressions) dimensions used. The susceptibility dimension measured the healthcare professionals' susceptibility to COVID-19. The seriousness dimension measured the perceived seriousness of the healthcare professionals regarding the COVID-19 issue and the associated anxiety and fear they experience. The benefit dimension measured the perceived benefits of the healthcare professionals about the use of personal protective equipment. Finally, the dimension of the barrier used to identify the barriers that impeded healthcare professionals' use of personal protective equipment. Studies have reported that the scale can be used in different situations. In this case, the scale used to measure healthcare professionals' perceptions regarding the COVID-19. The scale was designed with a 5-point Likert structure and scored as follows: 1 , strongly disagree, and 5, strongly agree. 
3. Perception of stigma and interpersonal scale. Maunder et al. [16] developed the scale, which consisted of 4 expressions and measured the health professionals' perceptions of stigma and individual isolation regarding their profession. The scale was designed with a 5-point Likert structure and scored as follows: 1 , strongly disagree, and 5, strongly agree.

The data of the study were collected using the online survey method. An online questionnaire link was sent to the participants by the hospital administration. The volunteers of the participants completed the questionnaire. Before the study, approvals of the Ethics Committee of Sakarya University, Commission for Scientific Research from the Ministry of Health of Turkey, and Sakarya Provincial Health Directorate were obtained.

Reliability analysis and descriptive statistical methods were used to analyze the data obtained with SPSS package program version 22.0.

\section{Results}

The participants of this study included 170 women and 46 men. Most of them were undergraduate $(32.4 \%)$, or associate $(35.6 \%)$ graduates. A total of 139 participants have children. There were 32 doctors, 61 nurses, and 123 other healthcare professionals (laboratory staff, radiology technician, medical secretary, etc.). There are COVID-19 positive healthcare workers in the unit where 100 of the participants' work. One hundred thirty-six of the participants think that enough measures have been taken across the country for COVID-19. The ages of the participants varied between 21 and 57 years, with an average of $34.29( \pm 7.00)$ years. The participants' professional experience varied between 1 and 31 years, with an average of $10.06( \pm 6.56)$ years.

In this study, the reliability analysis findings of the scales are shown in Table 1 . The reliability values of the scales varied between 0.60 and 0.91 . Accordingly, the reliability value of the stigma and avoidance dimension was at an acceptable level. Moreover, the reliability of the susceptibility and barriers dimensions were well, whereas those of the seriousness and benefit dimensions were high.

As shown in Table 2, the average responses are provided for the scales. According to these results, it can be noted that the participants' susceptibility to the COVID-19 (3.57 \pm 0.81$)$ and their perceived stigma
Table 1

Cronbach's alpha values

\begin{tabular}{lcc}
\hline & Cronbach's alpha & Number of items \\
\hline Susceptibility & 0.81 & 6 \\
Seriousness & 0.91 & 12 \\
Benefit & 0.85 & 5 \\
Barriers & 0.80 & 8 \\
Stigma and avoidance & 0.63 & 4 \\
\hline
\end{tabular}

Table 2

Mean and standard deviation

\begin{tabular}{lcc}
\hline & Mean & Standard deviation \\
\hline Susceptibility & 3.57 & 0.81 \\
Seriousness & 2.78 & 0.85 \\
Benefit & 4.25 & 0.63 \\
Barriers & 3.21 & 0.78 \\
Stigma and avoidance & 3.46 & 0.68 \\
\hline
\end{tabular}

and avoidance $(3.46 \pm 0.68)$ are above the middle level, and the benefit perceptions are at a high level $(4.25 \pm 0.63)$.

Table 3 shows the frequencies and percentages of the participant's responses to the scale expressions. According to the results, the rate of participants participating in the option "I have a high risk of infection with the COVID-19" is $80.4 \%$. On the other hand, the participation rate of the participants to the statement "The conditions are very favourable for me to be infected with the COVID-19" is $64 \%$. Furthermore, the rate of the participants agreeing to the statement "I consider that I am favourably infected with the COVID-19 in the coming days" is $48.8 \%$. These findings show that healthcare workers think they are at serious risk of contracting COVID-19 and are therefore worried.

When examined the answers given by the participants to the questions about the seriousness of COVID-19, $51.9 \%$ of the participants agreed with the statement "The mind of being affected by COVID-19 frightens me"; $58.9 \%$ participated in the statement "My social relationships can be compromised if I will be infected with the COVID-19" and $55.1 \%$ confirmed the statement "If I will be infected with the COVID-19, its negative effects may take a long time". These results show that employees are afraid of getting COVID-19 and believe it will affect them negatively.

Participants generally showed a high level of participation in the questions posed to them about the benefits of using protective equipment. As seen in Table 3, almost all participants $(96.20 \%)$ agreed with the statement, "It is a wise precaution to use personal 
Table 3

Frequencies of the answers provided by the participants

\begin{tabular}{|c|c|c|c|c|c|c|}
\hline & & 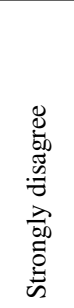 & 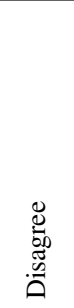 & 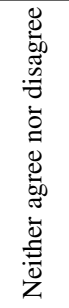 & 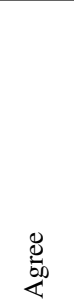 & 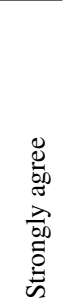 \\
\hline \multicolumn{7}{|l|}{ Susceptibility } \\
\hline \multirow[t]{2}{*}{ I have a high risk of infection with the coronavirus } & $\mathrm{n}$ & 0 & 15 & 16 & 61 & 66 \\
\hline & $\%$ & 0.0 & 9.5 & 10.1 & 38.6 & 41.8 \\
\hline \multirow{2}{*}{$\begin{array}{l}\text { The status of my physical health increases the risk of infection } \\
\text { with the coronavirus }\end{array}$} & $\mathrm{n}$ & 12 & 55 & 36 & 35 & 20 \\
\hline & $\%$ & 7.6 & 34.8 & 22.8 & 22.2 & 12.7 \\
\hline \multirow{2}{*}{$\begin{array}{l}\text { I consider that I am likely to be infected with the coronavirus in } \\
\text { the coming days }\end{array}$} & $\mathrm{n}$ & 2 & 23 & 56 & 49 & 28 \\
\hline & $\%$ & 1.3 & 14.6 & 35.4 & 31.0 & 17.7 \\
\hline \multirow{2}{*}{$\begin{array}{l}\text { The conditions are very favorable for me to be infected with the } \\
\text { coronavirus }\end{array}$} & $\mathrm{n}$ & 2 & 21 & 34 & 63 & 38 \\
\hline & $\%$ & 1.3 & 13.3 & 21.5 & 39.9 & 24.1 \\
\hline \multirow[t]{2}{*}{ I am very worried about being infected withthe coronavirus } & $\mathrm{n}$ & 11 & 42 & 28 & 46 & 31 \\
\hline & $\%$ & 7.0 & 26.6 & 17.7 & 29.1 & 19.6 \\
\hline \multirow{2}{*}{$\begin{array}{l}\text { I consider that I will be infected withthe coronavirus in the } \\
\text { coming days }\end{array}$} & $\mathrm{n}$ & 5 & 32 & 63 & 36 & 22 \\
\hline & $\%$ & 3.2 & 20.3 & 39.9 & 22.8 & 13.9 \\
\hline \multicolumn{7}{|l|}{ Seriousness } \\
\hline \multirow[t]{2}{*}{ The mind of being affected by coronavirus frightens me } & $\mathrm{n}$ & 9 & 32 & 35 & 52 & 30 \\
\hline & $\%$ & 5.7 & 20.3 & 22.2 & 32.9 & 19.0 \\
\hline \multirow[t]{2}{*}{ I feel bad when I think about the coronavirus } & $\mathrm{n}$ & 25 & 74 & 15 & 31 & 13 \\
\hline & $\%$ & 15.8 & 46.8 & 9.5 & 19.6 & 8.2 \\
\hline \multirow{2}{*}{$\begin{array}{l}\text { My career could be compromised if I will be infected with the } \\
\text { coronavirus }\end{array}$} & $\mathrm{n}$ & 32 & 85 & 26 & 8 & 7 \\
\hline & $\%$ & 20.3 & 53.8 & 16.5 & 5.1 & 4.4 \\
\hline \multirow[t]{2}{*}{ My heart rate increases when I think of the coronavirus } & $\mathrm{n}$ & 32 & 77 & 12 & 25 & 12 \\
\hline & $\%$ & 20.3 & 48.7 & 7.6 & 15.8 & 7.6 \\
\hline \multirow{2}{*}{$\begin{array}{l}\text { My social relationships can be compromised if I will be } \\
\text { infected with the coronavirus }\end{array}$} & $\mathrm{n}$ & 22 & 30 & 13 & 55 & 38 \\
\hline & $\%$ & 13.9 & 19.0 & 8.2 & 34.8 & 24.1 \\
\hline \multirow[t]{2}{*}{ Coronavirus is an urgent disease } & $\mathrm{n}$ & 35 & 70 & 37 & 7 & 9 \\
\hline & $\%$ & 22.2 & 44.3 & 23.4 & 4.4 & 5.7 \\
\hline \multirow{2}{*}{$\begin{array}{l}\text { If I will be infected with the coronavirus, my thoughts about } \\
\text { myself will change }\end{array}$} & $\mathrm{n}$ & 33 & 71 & 33 & 15 & 6 \\
\hline & $\%$ & 20.9 & 44.9 & 20.9 & 9.5 & 3.8 \\
\hline \multirow[t]{2}{*}{ I am even afraid to think of the coronavirus } & $\mathrm{n}$ & 33 & 73 & 23 & 23 & 6 \\
\hline & $\%$ & 20.9 & 46.2 & 14.6 & 14.6 & 3.8 \\
\hline \multirow{2}{*}{$\begin{array}{l}\text { My economic situation may worsen if I will be infected with } \\
\text { the coronavirus }\end{array}$} & $\mathrm{n}$ & 30 & 50 & 26 & 30 & 22 \\
\hline & $\%$ & 19.0 & 31.6 & 16.5 & 19.0 & 13.9 \\
\hline \multirow{2}{*}{$\begin{array}{l}\text { If I will be infected with the coronavirus, its negative effects } \\
\text { may take a long time }\end{array}$} & $\mathrm{n}$ & 7 & 28 & 36 & 55 & 32 \\
\hline & $\%$ & 4.4 & 17.7 & 22.8 & 34.8 & 20.3 \\
\hline \multirow[t]{2}{*}{ Being infected with the coronavirus is worse than other diseases } & $\mathrm{n}$ & 17 & 56 & 39 & 27 & 19 \\
\hline & $\%$ & 10.8 & 35.4 & 24.7 & 17.1 & 12.0 \\
\hline \multirow[t]{2}{*}{ My life can change if I will be infected withthe coronavirus } & $\mathrm{n}$ & 22 & 54 & 41 & 26 & 15 \\
\hline & $\%$ & 13.9 & 34.2 & 25.9 & 16.5 & 9.5 \\
\hline
\end{tabular}


Table 3

(Continued)

\begin{tabular}{|c|c|c|c|c|c|c|}
\hline & & 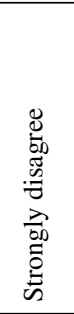 & 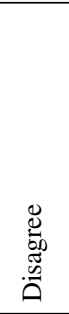 & 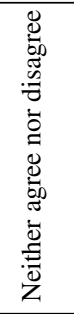 & $\underset{\circlearrowright}{\circlearrowright}$ & 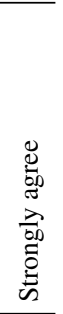 \\
\hline \multicolumn{7}{|l|}{ Benefit } \\
\hline \multirow[t]{2}{*}{$\begin{array}{l}\text { The use of personal protective equipment prevents problems } \\
\text { that I may encounter }\end{array}$} & $\mathrm{n}$ & 7 & 4 & 25 & 94 & 28 \\
\hline & $\%$ & 4.4 & 2.5 & 15.8 & 59.5 & 17.7 \\
\hline \multirow[t]{2}{*}{ The use of personal protective equipment can greatly save me } & $\mathrm{n}$ & 5 & 3 & 12 & 98 & 40 \\
\hline & $\%$ & 3.2 & 1.9 & 7.6 & 62.0 & 25.3 \\
\hline \multirow[t]{2}{*}{$\begin{array}{l}\text { The use of personal protective equipment reduces the risk of } \\
\text { infection with the coronavirus }\end{array}$} & $\mathrm{n}$ & 3 & 2 & 9 & 91 & 53 \\
\hline & $\%$ & 1.9 & 1.3 & 5.7 & 57.6 & 33.5 \\
\hline \multirow{2}{*}{$\begin{array}{l}\text { When treating patients infected with the coronavirus, I should } \\
\text { use personal protective equipment }\end{array}$} & $\mathrm{n}$ & 3 & 2 & 2 & 46 & 105 \\
\hline & $\%$ & 1.9 & 1.3 & 1.3 & 29.1 & 66.5 \\
\hline \multirow{2}{*}{$\begin{array}{l}\text { It is a wise precaution to use personal protective equipment } \\
\text { when treating patients infected with the coronavirus }\end{array}$} & $\mathrm{n}$ & 3 & 0 & 3 & 47 & 105 \\
\hline & $\%$ & 1.9 & 0.0 & 1.9 & 29.7 & 66.5 \\
\hline \multicolumn{7}{|l|}{ Barriers } \\
\hline \multirow{2}{*}{$\begin{array}{l}\text { It is difficult to take care of patients while using personal } \\
\text { protective equipment }\end{array}$} & $\mathrm{n}$ & 3 & 16 & 18 & 55 & 66 \\
\hline & $\%$ & 1.9 & 10.1 & 11.4 & 34.8 & 41.8 \\
\hline \multirow[t]{2}{*}{ Using personal protective equipment is uncomfortable } & $\mathrm{n}$ & 3 & 12 & 13 & 72 & 58 \\
\hline & $\%$ & 1.9 & 7.6 & 8.2 & 45.6 & 36.7 \\
\hline \multirow{2}{*}{$\begin{array}{l}\text { The use of personal protective equipment makes it difficult to } \\
\text { perform my professional ability }\end{array}$} & $\mathrm{n}$ & 10 & 45 & 36 & 41 & 26 \\
\hline & $\%$ & 6.3 & 28.5 & 22.8 & 25.9 & 16.5 \\
\hline \multirow{2}{*}{$\begin{array}{l}\text { The drawbacks of using personal protective equipment may be } \\
\text { more than its benefits }\end{array}$} & $\mathrm{n}$ & 34 & 88 & 26 & 9 & 1 \\
\hline & $\%$ & 21.5 & 55.7 & 16.5 & 5.7 & 0.6 \\
\hline \multirow{2}{*}{$\begin{array}{l}\text { My coworkers make fun of me while using personal protective } \\
\text { equipment }\end{array}$} & $\mathrm{n}$ & 77 & 65 & 7 & 6 & 3 \\
\hline & $\%$ & 48.7 & 41.1 & 4.4 & 3.8 & 1.9 \\
\hline \multirow{2}{*}{$\begin{array}{l}\text { The use ofpersonal protective equipment affects my } \\
\text { relationships with patients }\end{array}$} & $\mathrm{n}$ & 34 & 59 & 25 & 33 & 7 \\
\hline & $\%$ & 21.5 & 37.3 & 15.8 & 20.9 & 4.4 \\
\hline \multirow{2}{*}{$\begin{array}{l}\text { Wearing protective devices would require starting a new habit, } \\
\text { which is difficult }\end{array}$} & $\mathrm{n}$ & 12 & 37 & 27 & 58 & 24 \\
\hline & $\%$ & 7.6 & 23.4 & 17.1 & 36.7 & 15.2 \\
\hline \multirow{2}{*}{$\begin{array}{l}\text { The use of personal protective equipment causes more } \\
\text { problems than the protection it offers }\end{array}$} & $\mathrm{n}$ & 36 & 85 & 27 & 8 & 2 \\
\hline & $\%$ & 22.8 & 53.8 & 17.1 & 5.1 & 1.3 \\
\hline \multicolumn{7}{|l|}{ Stigma and avoidance } \\
\hline \multirow{2}{*}{ I think that people are avoiding me because of my job } & $\mathrm{n}$ & 17 & 32 & 46 & 47 & 16 \\
\hline & $\%$ & 10.8 & 20.3 & 29.1 & 29.7 & 10.1 \\
\hline \multirow[t]{2}{*}{ I think that people are avoiding my family because of my job } & $\mathrm{n}$ & 21 & 62 & 36 & 29 & 10 \\
\hline & $\%$ & 13.3 & 39.2 & 22.8 & 18.4 & 6.3 \\
\hline \multirow{2}{*}{$\begin{array}{l}\text { I take precaution by avoiding crowded places because of the } \\
\text { coronavirus }\end{array}$} & $\mathrm{n}$ & 2 & 1 & 5 & 74 & 76 \\
\hline & $\%$ & 1.3 & $0, .6$ & 3.2 & 46.8 & 48.1 \\
\hline \multirow{2}{*}{$\begin{array}{l}\text { I take precaution by distancing myself from my coworkers } \\
\text { because of the coronavirus }\end{array}$} & $\mathrm{n}$ & 2 & 21 & 29 & 81 & 25 \\
\hline & $\%$ & 1.3 & 13.3 & 18.4 & 51.3 & 15.8 \\
\hline
\end{tabular}


protective equipment when treating patients infected with the COVID-19”. In addition, the participants highly agreed with the statements "When treating patients infected with the COVID-19, I should use personal protective equipment" with $95.60 \%$ and "The use of personal protective equipment reduces the risk of infection with the COVID-19" with $91.10 \%$. These results show that the participants are aware of the importance and benefits of using protective equipment.

When examining the answers given by the participants to the questions about the negative aspects of the use of protective equipment, $82.30 \%$ of the participants stated, "Using personal protective equipment is uncomfortable"; $76.60 \%$ said "It is difficult to take care of patients while using personal protective equipment" and 51.90\% said "Wearing protective devices would require starting a new habit, which is difficult". These results show that protective equipment makes working conditions and service provision difficult for healthcare workers.

When examined the answers given by the participants to the questions about the stigmatization and isolation of healthcare workers, $94.90 \%$ of the participants agreed with the statement "I take precaution by avoiding crowded places because of the COVID-19". $67.10 \%$ of the participants agreed with the statement "I take precaution by distancing myself from my coworkers because of the COVID-19". Accordingly, the participants are moving away from crowded environments and their colleagues within the scope of measures for COVID-19.

\section{Discussion}

During the pandemic process, intensive work, communicating with infected patients, and intensive personal protective equipment have affected healthcare professionals mentally. Therefore, this study aimed to determine healthcare professionals' perceptions, experiences, and attitudes regarding the COVID-19.

According to the study's findings, healthcare professionals believe that the COVID-19 is not an urgent disease. However, they are afraid of being infected with the COVID-19. Moreover, they consider that possible infection with the COVID-19 will adversely affect their social relationships and economic situations, and its adverse effects will continue for a long time. The high COVID-19 infection rate and the high risk of death cause people to be afraid of being infected with COVID-19 [18], which gradually increases [19]. As an explanation, health professionals who had direct contact with infected individuals likely experience this fear. In addition, incomplete or incorrect information about COVID-19 pandemics increases the anxiety levels of healthcare professionals [20].

Healthcare professionals' feelings of being excluded and stigmatized are the harmful effects of the COVID-19 pandemic. According to the study results, it is a significant index that health professionals think that people are trying to avoid them. The fear experienced by society in such periods of infectious disease can cause stigmatization [21]. According to the Centers for Disease Control and Prevention [22], stigma is the tendency of individuals to blame a disease or some groups for fear of death and threaten the stigmatized groups' emotional, mental, and physical health. Especially, healthcare professionals are recognized as the high-risk group in terms of stigma, as they directly handle infected individuals. The idea that healthcare professionals who are in direct contact with COVID-19-positive patients will also fall ill with the disease and spread the virus to others may cause society to avoid them.

In this study, another significant result shows that healthcare professionals consider that they will be infected with the COVID-19 and conditions are very favourable for them to fall ill with the disease. According to Wang et al. [23], healthcare professionals are at an increased risk of being infected due to prolonged exposure to many infected patients and increased workload. Additionally, the lack of personal protective equipment poses a significant risk for healthcare professionals [20]. Under these situations, it is a normal consequence that health professionals who are in contact with infected patients believe that they may also be infected.

A study concluded that the most significant factor in protecting healthcare professionals from COVID19 is the usage of personal protective equipment [17]. According to the study results, the opinions of health professionals about the benefits of using personal protective equipment support this argument. They consider that the use of personal protective equipment is a well-advised measure, reduces possible risks, and can save them from the disease. This result shows that healthcare professionals have a positive attitude toward using personal protective equipment. $\mathrm{Wu}$ et al. [24] also advise healthcare professionals to approach patients diagnosed with or suspected of COVID-19 with personal protec- 
tive equipment. Healthcare professionals can only be protected from possible risks with the precautions to be taken. In this regard, the present study shows that healthcare professionals consider that getting used to personal protective equipment is complex, service with personal protective equipment is complicated and personal protective equipment are restricting their professional skills. However, they consider that personal protective equipment does not affect the patient-healthcare professionals' relationship and personal protective equipment are beneficial for their protection.

\section{Conclusion}

The pandemic process causes two significant pressures on healthcare professionals [17]: (1) the overwhelmingly increased workload and (2) the risk of becoming infected. The current study demonstrated that healthcare workers who constantly contact infected patients and use intensive protective equipment could mentally affect healthcare professionals during the pandemic process.

The study results showed that healthcare professionals have positive thoughts about personal protective equipment and attitudes toward personal protective equipment because of its associated benefit personal protective equipment. The present study also found that healthcare professionals have a negative perception of COVID-19, but they have a positive attitude and behaviour about COVID-19 protection. Moreover, it is observed that healthcare professionals experience fear and anxiety about being infected with the COVID-19. From the literature, fear and anxiety experienced in pandemic processes negatively affect health and well-being [21, 25]. As considered these findings, mental health support of healthcare professionals is vital for both well-being and health services.

Additionally, it is necessary to focus on the health professionals who feel excluded from society. The adverse effects of such stigmatization on professionals will affect not only them but also public health. Therefore, it is highly significant to investigate whether society has a negative opinion toward healthcare professionals and take measures against a possible negative attitude in terms of healthcare professionals' psychological well-being. Raising the awareness of society in this regard is another essential step that should be taken. A recent study conducted during the COVID-19 pandemic has supposed that the social support perceived by professionals reduces their anxiety levels [26]. Based on other studies, another significant issue in the COVID-19 pandemic process is the usage of personal protective equipment. The current study results reveal that healthcare professionals have a positive attitude toward the usage of personal protective equipment. Therefore, rewarding and supporting of usage of personal protective equipment is essential for the continuation of this behaviour.

\section{Limitation}

Conducting the study using the online survey technique under COVID-19 pandemic conditions constitutes a significant limitation. Although the online survey technique offers some advantages, it has some risks. The most important of these risks is that it limits the researcher to help when they do not understand the questions or have something on their minds. Another limitation of the study is that the study was conducted only in a pandemic hospital. The fact that other pandemic hospitals in the province did not participate in the study because researchers could not obtain permission due to pandemic conditions restricts the generalizability of the study.

\section{Conflict of interest}

The authors declare no potential conflicts of interest with respect to the research, authorship, and/or publication of this article.

\section{Funding}

The authors received no financial support for the research, authorship, and/or publication of this article.

\section{References}

[1] World Health Organization [homepage on the Internet]. Geneva: WHO Characterizes COVID-19 as a pandemic; 2020 [updated 2020 March 11; cited 2021 April 26]. Available from: https://www.who.int/emergencies/diseases/nov el-coronavirus-2019/events-as-they-happen.

[2] Saqlain M, Munir M, Rehman S, Gulzar A, Naz S, Ahmed Z, Tahir AH, Mashhood M. Knowledge, attitude, practice and perceived barriers among healthcare workers regard- 
ing COVID-19: a crosssectional survey from Pakistan. Journal of Hospital Infection. 2020;105(3):419-423. doi: https://doi.org/10.1016/j.jhin.2020.05.007

[3] Babamiri M, Alipour N, Heidarimoghadam R. Research on reducing burnout in health care workers in critical situations such as the COVID-19 outbreak. Work. 2020;66(2):379-80. doi: https://doi.org/10.3233/WOR-203189

[4] Huynh G, Nguyen TN, Tran VK, Vo KN, Vo VT, Pham LA. Knowledge and attitude toward covid-19 among healthcare workers at district 2 hospital, Ho Chi Minh City. Asian Pacific Journal of Tropical Medicine. 2020;13(6):260-5. doi: https://doi.org/10.4103/1995-7645.280396

[5] Dalky HF, Ghader N, Al Kuwari M, Alnajar M, Ismaile S, Almalik M, Shudifat R, Sanad S, Al-Nsair N, Al Matrooshi F. Assessment of the awareness, perception, attitudes, and preparedness of healthcare professionals potentially exposed to COVID-19 in the United Arab Emirates. J Multidiscip Healthc. 2021;14:91-102. doi: https://doi.org/10.2147/JMDH.S278479

[6] Feiz Arefi M, Babaei-Pouya A, Poursadeqiyan M. The health effects of quarantine during the COVID-19 pandemic. Work. 2020;67(2):523-7. doi: https://doi.org/ 10.3233/WOR-203306

[7] Ünal, Ö. During COVID-19, which is more effective in work accident prevention behavior of healthcare professionals: safety awareness or fatalism perception? Work. 2020;67(4):783-90. doi: https://doi.org/10.3233/WOR-203 327

[8] Hesaraki M, Akbarizadeh M, Ahmadidarrehsima S, Moghadam MP, Izadpanah F. Knowledge, attitude, practice and clinical recommendations of health care workers towards COVID-19: a systematic review. Reviews on Environmental Health. 2020;1-13. doi: https://doi.org/10.1515/ reveh-2020-0099

[9] Omrani AS, Shalhoub S. Middle east respiratory syndrome coronavirus (MERS-CoV): what lessons can we learn? Journal of Hospital Infection. 2015;91(3):188-96. doi: http://dx.doi.org/10.1016/j.jhin.2015.08.002\%2001956701

[10] Upadhyaya DP, Paudel R, Acharya D, Khoshnood K, Lee K, Park JH, Yoo SJ, Shrestha A, BC B, Bhandari S, Yadav R, Timalsina A, Wagle CN, Das BK, Kunwar R, Chalise B, Bhatta DR, Adhikari M. Frontline healthcare workers' knowledge and perception of COVID-19, and willingness to work during the pandemic in Nepal. Healthcare. 2020;8(4):554. doi: https://doi.org/10.3390/ healthcare8040554

[11] Malik UR, Atif N, Hashmi FK, Saleem F, Saeed H, Islam M, Jiang M, Zhao M, Yang C, Fang Y. Knowledge, attitude, and practices of healthcare professionals on COVID-19 and risk assessment to prevent the epidemic spread: a multicenter cross-sectional study from Punjab, Pakistan. International Journal of Environmental Research and Public Health. 2020;17(17):6395. doi: https://doi.org/10.3390/ ijerph17176395

[12] Abdel Wahed WY, Hefzy EM, Ahmed MI, Hamed NS. Assessment of knowledge, attitudes, and perception of health care workers regarding COVID-19, a crosssectional study from Egypt. Journal of Community Health. 2020;45:1242-51. doi: https://doi.org/10.1007/s10900-02000882-0
[13] Zhang M, Zhou M, Tang F, Wang Y, Nie H, Zhang L, You G. Knowledge, attitude, and practice regarding COVID-19 among healthcare workers in Henan, China. Journal of Hospital Infection. 2020;105(2):183-7. doi: https://doi.org/10.1016/j.jhin.2020.04.012

[14] Champion VL. Instrument development for health belief model constructs. Advances in Nursing Science. 1984;6(3):73-85.

[15] Bova BL. The health belief model and personality type as predictors of personal protective equipment use by critical care nurses at risk for exposure to tuberculosis (Doctoral dissertation, New York University). 2004.

[16] Maunder RG, Lancee WJ, Balderson KE, Bennett, JP, Borgundvaag B, Evans S, Fernandes CM, Goldbloom DS, Gupta M, Hunter JJ, McGillis Hall L, Nagle LM, Pain C, Peczeniuk SS, Raymond G, Read N, Rourke SB, Steinberg RJ, Stewart TE, VanDeVelde-Coke S, Veldhorst GG, Wasylenki DA. Long-term psychological and occupational effects of providing hospital healthcare during SARS outbreak. Emerging Infectious Diseases. 2006;12(12):1924-32.

[17] Adams JG, Walls RM. Supporting the health care workforce during the COVID-19 global epidemic. Jama. 2020; 323(15):1439-40.

[18] Ahorsu DK, Lin CY, Imani V, Saffari M, Griffiths MD, Pakpour AH. The fear of COVID-19 scale: development and initial validation. International Journal of Mental Health and Addiction. 2020;1-9. Advance online publication.

[19] Lin CY. Social reaction toward the 2019 novel coronavirus (COVID-19). Social Health and Behavior. 2020;3(1):1-2.

[20] Schwartz J, King CC, Yen MY. Protecting healthcare workers during the coronavirus disease 2019 (COVID-19) outbreak: lessons from taiwan's severe acute respiratory syndrome response. Clinical Infectious Diseases. 2020;71(15):858-60.

[21] Pappas G, Kiriaze IJ, Giannakis P, Falagas ME. Psychosocial consequences of infectious diseases. Clinical Microbiology and Infection. 2009;15(8):743-7.

[22] Centers for Disease Control and Prevention [homepage on the Internet]. Coronavirus disease 2019 (COVID19): Reducing stigma. 2020 [updated 2020 June 11; cited 2020 June 26]. Available from: https://www.cdc.gov/ coronavirus/2019-ncov/about/related-stigma.html.

[23] Wang J, Zhou M, Liu F. Reasons for healthcare workers becoming infected with novel coronavirus disease 2019 (COVID-19) in China. The Journal of Hospital Infection. 2020;105(1):100-101.

[24] Wu YC, Chen CS, Chan YJ. The outbreak of COVID-19: an overview. Journal of the Chinese Medical Association. 2020;83(3):217-20.

[25] Ropeik, D. The consequences of fear. EMBO Reports. 2004;5(Suppl 1):56-60.

[26] Xiao H, Zhang Y, Kong D, Li S, Yang N. The effects of social support on sleep quality of medical staff treating patients with coronavirus disease 2019 (COVID-19) in January and February 2020 in China. Medical Science Monitor: International Medical Journal of Experimental and Clinical Research. 2020;26:e923549-1. 